\title{
Performance, fatty acids profile and oxidative stability of meat of rabbits fed different lipid sources
}

\author{
Túlio Henrique Leite de ANDRADE ${ }^{1}$, Leonardo Augusto Fonseca PASCOAL ${ }^{1 *}$, \\ Terezinha Domiciano Dantas MARTINS ${ }^{1}$, José Humberto Vilar SILVA ${ }^{1}$, Jordanio Fernandes da SILVA ${ }^{1}$, \\ Pedro Henrique WATANABE ${ }^{2}$, Valquíria Cardoso da Silva FERREIRA ${ }^{1}$
}

\begin{abstract}
To evaluate the use of different lipid sources in diets of growing rabbits, 60 New Zealand White rabbits were evaluated on performance, carcass traits, meat composition, fatty acid profile and oxidative stability of refrigerated and frozen meat. The experiment was distributed in a randomized block design, in five treatments, with six replicates and two animals per experimental unit (one male and one female). The treatments consisted of five isonutritive diets, with $2.5 \%$ soybean oil (SO), sunflower oil (SFO), cottonseed oil (CO), beef tallow (BT) and poultry fat (PF). There was no effect $(\mathrm{P}>0.05)$ of dietary lipid sources on animal performance, carcass traits and meat composition $(\mathrm{P}>0.05)$. Dietary inclusion of beef tallow resulted in a lower proportion of polyunsaturated fatty acids in meat compared to vegetable oils. The values of thiobarbituric acid-reactive substances (TBARS) indicated higher oxidation in the frozen meat of the animals fed with sunflower oil, cottonseed oil and bovine tallow in their diets. In conclusion, vegetable oils and animal fats can be included in growing rabbit diets without impair performance and meat quality parameters. Dietary inclusion of soybean oil is more advantageous because it promotes the incorporation of polyunsaturated fatty acids and greater lipid stability of refrigerated and frozen rabbit meat.
\end{abstract}

Keywords: fat; oil; performance; peroxidation; rabbit meat; PUFA.

Practical Application: Soybean oil is the best lipid source to be used in rabbit diets. The use of sunflower oil, cottonseed oil and beef tallow in growing rabbit diets may imply the addition of antioxidants to protect against the effects of lipid peroxidation.

\section{Introduction}

Considering the nutritional requirements of growing rabbits, the inclusion of lipid sources in diet, besides improving pellet quality, helps to meet the energy demands of the animals, as the adjustment of voluntary feed intake by rabbits is primarily controlled by the energy content of the diet (Gidenne et al., 2017). As the energy content of lipid sources is almost three times that other feedstuffs commonly used, the inclusion of oils and fats in rabbit diets allows a greater share of ingredients with higher fibre contents to be included, such as by-products from food and feed processing industries (Klinger et al., 2015).

Factors related to fatty acid profiles, including physicochemical characteristics and interactions, as well as the length and degree of saturation, directly influence the digestibility of lipids and other nutrients by rabbits (Cesari et al., 2009; Casado et al., 2010). Along with the positive effects observed with the inclusion of lipid sources in growing rabbit diets (Fernández \& Fraga, 1996; El-Husseiny et al., 2004), it has been observed that the incorporation of dietary fatty acids directly into adipose and intramuscular tissue is an important factor for human nutrition, through the strategic inclusion of vegetable oils (Dalle Zotte, 2002; Souza et al., 2009). In turn, the use of animal fat in rabbit diets could also be feasible due to the lower cost, although the higher presence of saturated fatty acids as well as the thermal oxidation in the processing of these lipid sources may negatively affect nutrient digestibility (Casado et al., 2010) and consequently animal performance.

In this sense, besides the modulation of intramuscular fatty acid profile as well as the increase of $n-3$ essential fatty acids from the inclusion of oils and fats in diet (Petracci et al., 2009), there is still a concern about the effects of increased polyunsaturated fatty acids through dietary inclusion of oils on susceptibility to peroxidation through rapid development of oxidative rancidity in meat (Tres et al., 2008), and also reducing shelf-life.

Therefore, the aim of the present study was to evaluate the dietary inclusion of vegetable oils (soybean oil, sunflower oil and cottonseed oil) and animal fats (beef tallow and poultry fat) on performance, carcass traits, meat composition, fatty acid profile and oxidative stability of refrigerated and frozen meat of rabbits.

*Corresponding author: leonardo@cchsa.ufpb.br, pascoallaf@pq.cnpq.br 


\section{Materials and methods}

\subsection{Experimental design and animal performance}

The experiment was conducted at the Rabbit Farming Laboratory at the Centro de Ciências Humanas, Sociais e Agrárias, Universidade Federal da Paraíba, Brazil. The experimental protocols used in this study were approved by the Animal Ethics Committee (Comissão de Ética no Uso de Animais - CEUA) of Universidade Federal da Paraíba (CEUA no 2006/13).

Sixty New Zealand White rabbits (30 males and 30 females), weaned at 30 days of age, with an initial average weight of $632.85 \pm 0.73 \mathrm{~g}$ were used in the study. The animals were distributed according to a randomized block design including five treatments, with six replicates and two animals per experimental unit (one male and one female). The animals were housed in metal cages in a brick barn. The mean temperature and relative humidity recorded inside the barn were $23.4 \pm 2{ }^{\circ} \mathrm{C}$ and $88.0 \pm 8 \%$, respectively. The treatments consisted of five isonutritives diets formulated with the inclusion of one of the following lipid sources at 2.5\%: soybean oil (SO), sunflower oil (SFO), cottonseed oil $(\mathrm{CO})$, beef tallow $(\mathrm{BT})$, and poultry fat $(\mathrm{PF})$. The diets were formulated to meet the nutritional requirements of growing rabbits according to Lebas (1999) and were provided in a dry pelleted form (Table 1). The animals had unlimited access to water and feed throughout the experimental period.

The animals, the feed, and the leftovers were weighed weekly to calculate the average daily gain, average daily feed intake, and feed conversion. At 80 days of age, the animals were fasted for 12 hours prior to slaughter and evisceration. The stunning application was performed by electrical method (140 mA) for subsequent bleeding and evisceration. The carcasses were evaluated to determine the hot carcass yield, cold carcass yield, and yield of commercial cuts. The fore legs, hind legs, breast and ribs, loin and thigh were weighed and expressed as percentage of cold carcass weight.

\subsection{Proximate composition of meat}

Samples of the Longissimus muscle were collected from the animals and ground and homogenized in a processor. The moisture, ash, and crude protein contents were determined according to Association of Official Analytical Chemists (1990) methods 950.46, 942.05 and 992.15, respectively. Lipids were extracted using the method reported by Folch et al. (1957).

Table 1. Nutritional composition of experimental diets for growing rabbits.

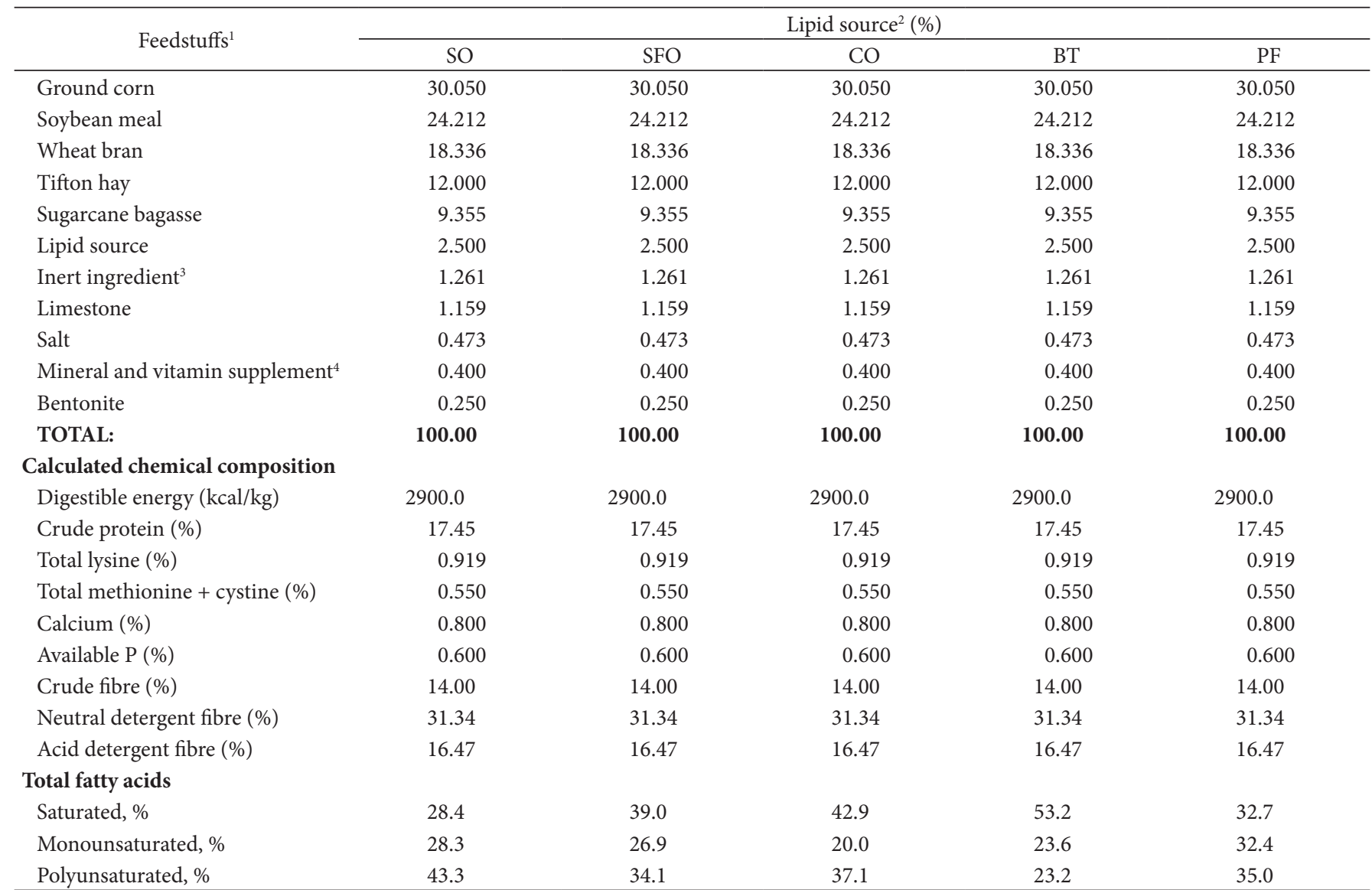

${ }^{1}$ Feedstuffs composition proposed by Lebas (1999); ${ }^{2}$ Lipid source: soybean oil (SO); sunflower oil (SFO); cottonseed oil (CO); beef tallow (BT); and poultry fat (PF); ${ }^{3}$ Sand; ${ }^{4}$ Vitamin supplement: Vit A, 600,000 IU; Vit D, 100,000 IU; Vit E, 8000 mg; Vit K3, 200 mg; Vit B1, 400 mg; Vit B2 600 mg; Vit B6, 200 mg; Vit B12, 2000 mcg; Pantothenic acid, 2000 mg; Choline, 70,000 mg; Fe, 8000 mg; Cu, 1200 mg; Co, 200 mg; Mn, 8600 mg; Zn, 12,000 mg; I, 64 mg; Se, 16 mg; Antioxidant 20,000 mg. 


\subsection{Fatty acid profile analysis}

After extraction of the lipid fraction, the extracts were esterified and sent to the Instrumental Chromatography Laboratory of the Centre for Technology and Geosciences of the Federal University of Pernambuco (Universidade Federal de Pernambuco - UFPE), Recife Campus, to determine the fatty acid profile by means of gas chromatography.

Samples subjected to transmethylation were analysed in a gas chromatograph (CG-MASTER) equipped with a flame ionization detector and an Hp Innowax capillary column $(30 \mathrm{~m} \times 0.25 \mathrm{~mm} \times 0.25 \mu \mathrm{m})$, injecting $1 \mu \mathrm{L}$ of the esterified extract. The carrier gas (hydrogen) flow rate was $5 \mathrm{~mL} / \mathrm{min}$ and authentic standard methyl esters of fatty acids (MERCK-USA) were used as standards. The identification of fatty acids was performed based on a comparison of retention times, and the percentages of fatty acids were calculated using the software Peaksimple (SRI Instruments - USA). The following fatty acids were quantified through normalization of the area of methyl esters: lauric (C12:0), myristic (C14:0), pentadecanoic (C15:0), palmitic (C16:0), palmitoleic (C16:1), margaric (C17:0), stearic (C18:0), oleic (C18:1), linoleic (C18:2), and linolenic (C18:3), and the results were expressed as a percentage (\%).

\subsection{Lipid oxidation determination}

The left leg was separated and deboned, the meat being grounded and homogenized in a processor. Lipid oxidation analyses in the thigh muscle were performed by determining the thiobarbituric acid reactive substances (TBARS), following the methodology described by Raharjo et al. (1992), with measurements conducted in a "Micronal" B582 spectrophotometer at $532 \mathrm{~nm}$, using a standard curve of 1,1,3,3-tetraethoxypropane (TEP) ranging from $5,7 \times 10^{-5}$ a $1,1 \times 10^{-3} \mathrm{mg} \mathrm{TEP} / \mathrm{mL}$. The meat samples were packed in polystyrene trays (Styrofoam) and covered with PVC film. The meats were stored in refrigerator $\left(5^{\circ} \mathrm{C}\right)$ and analyzed at 1 and 12 days under refrigeration to evaluate the shelf life of meat. Meat samples were frozen $\left(-18^{\circ} \mathrm{C}\right)$ and analyzed after 1 ,
15 and 30 days of frozen storage, considering the average storage time of frozen meat of up to 30 days.

\subsection{Statistical analysis}

All data were subjected to analysis of variance using the GLM (general linear models) procedure using the SAS (Statistical Analysis System - University Edition) statistical program, and the means were compared using Tukey's test at $5 \%$ of probability. The normality of the error was tested using the Cramer-von Misses test. For the TBA value of refrigerated meat, a randomized block design was applied in a $5 \times 2$ factorial arrangement, including 5 lipid sources and 2 storage periods ( 1 and 12 days). For the TBA value of frozen meat, a randomized block design was applied in a $5 \times 3$ factorial arrangement, including 5 lipid sources and 3 storage periods (1,15 and 30 days). For the TBA value of refrigerated and frozen meat, the means were compared using Tukey's test at $5 \%$ of probability.

\section{Results}

No effect on performance was observed in rabbits fed diet with different lipid sources $(P>0.05)$. Likewise, there was no effect of different lipid sources on carcass traits of rabbits. (Table 2).

The dietary lipid sources did not affect $(P>0.05)$ the proximate composition of rabbit meat (Table 3 ). Regarding the fatty acid profile, the dietary inclusion of cottonseed oil, beef tallow, and poultry fat resulted in a higher palmitic acid content (C16:0) in rabbit meat (Table 4), compared to meat from rabbits fed diet containing sunflower oil. In turn, lower values of palmitic acid in meat were observed in rabbits fed diets containing soybean oil.

The rabbits fed diet with beef tallow showed a higher total saturated fatty acid content in meat than those fed diet containing soybean oil, although no difference was observed in relation to other treatments. Higher level of linoleic acid (C18:2n6) were observed in meat from rabbits fed diet with vegetable oils than those from rabbits fed diet containing beef tallow, although no difference was observed in relation to meat from rabbits fed diet with poultry fat as lipid source. Higher level of linolenic acid

Table 2. Performance and carcass traits of rabbits fed diets containing different lipid sources.

\begin{tabular}{|c|c|c|c|c|c|c|c|}
\hline \multirow{2}{*}{ Variables $^{1}$} & \multicolumn{5}{|c|}{ Lipid sources $^{2}$} & \multirow{2}{*}{ SEM $^{3}$} & \multirow{2}{*}{$P$ value } \\
\hline & SO & SFO & $\mathrm{CO}$ & BT & $\mathrm{PF}$ & & \\
\hline FI (g/day) & 91.76 & 88.85 & 90.03 & 91.76 & 95.66 & 0.79 & 0.55 \\
\hline WG (g/day) & 26.60 & 27.24 & 27.33 & 27.79 & 31.02 & 0.28 & 0.09 \\
\hline FC & 3.45 & 3.27 & 3.32 & 3.26 & 3.09 & 0.31 & 0.36 \\
\hline SW (g) & 1903.20 & 2001.67 & 1965.40 & 1985.17 & 2134.50 & 1.32 & 0.13 \\
\hline $\operatorname{HCY}(\%)$ & 50.00 & 50.31 & 49.34 & 49.02 & 50.62 & 1.86 & 0.13 \\
\hline BRY (\%) & 40.41 & 39.09 & 38.50 & 38.40 & 39.61 & 2.62 & 0.90 \\
\hline HY (\%) & 35.86 & 36.66 & 36.56 & 37.33 & 36.23 & 1.42 & 0.82 \\
\hline LY (\%) & 15.58 & 15.02 & 16.28 & 16.32 & 17.13 & 1.81 & 0.08 \\
\hline TY (\%) & 30.76 & 32.18 & 32.94 & 32.52 & 30.62 & 2.19 & 0.50 \\
\hline
\end{tabular}

${ }^{1} \mathrm{FI}=$ Feed intake; $\mathrm{WG}=$ Weight gain; FC = Feed conversion; $\mathrm{SW}=$ slaughter weight; HCY = Hot carcass yield; CCY = Cold carcass yield; FY = Fore legs yield; BRY = Breast and ribs yield; HY = Hind legs yield; LY = Loin yield; TY = Thigh yield; ${ }^{2}$ Lipid sources: soybean oil (SO); sunflower oil (SFO); cottonseed oil (CO); beef tallow (BT); and poultry fat (PF); ${ }^{3} \mathrm{SEM}=$ Standard error of mean. 
Table 3. Proximate composition of meat from rabbits fed diets with different lipid sources.

\begin{tabular}{ccccc}
\hline \multirow{2}{*}{ Lipid sources } & \multicolumn{3}{c}{ Components (\%) } \\
\cline { 2 - 5 } & Moisture & Protein & Lipids & 6.01 \\
Soybean oil & 70.20 & 21.98 & 5.85 & 1.09 \\
Sunflower oil & 70.74 & 22.14 & 5.61 & 1.09 \\
Cottonseed oil & 69.03 & 21.33 & 6.17 & 1.04 \\
Beet tallow & 70.99 & 22.91 & 6.08 & 1.09 \\
Poultry fat & 70.72 & 21.52 & 0.98 & 1.13 \\
SEM $^{1}$ (\%) & 2.07 & 1.70 & 0.91 & 0.05 \\
P value & 0.91 & 0.86 & & 0.21 \\
\hline
\end{tabular}

${ }^{1} \mathrm{SEM}=$ Standard error of mean.

Table 4. Fatty acid profile of meat from rabbits fed diets with different lipid sources.

\begin{tabular}{|c|c|c|c|c|c|c|c|}
\hline \multirow{2}{*}{ Fatty acids } & \multicolumn{5}{|c|}{ Lipid sources $^{1}$} & \multirow{2}{*}{ SEM $^{2}$} & \multirow{2}{*}{$P$ value } \\
\hline & $\mathrm{SO}$ & SFO & $\mathrm{CO}$ & $\mathrm{BT}$ & $\mathrm{PF}$ & & \\
\hline \multicolumn{8}{|l|}{ Saturated } \\
\hline C12:0 (Lauric) & 3.84 & 4.89 & 6.85 & 10.03 & 6.96 & 2.36 & 0.15 \\
\hline C14:0 (Myristic) & 2.55 & 2.63 & 2.70 & 2.88 & 2.80 & 0.66 & 0.97 \\
\hline C15:0 (Pentadecanoic) & 0.78 & 0.80 & 0.67 & 0.72 & 0.67 & 0.15 & 0.80 \\
\hline C16:0 (Palmitic) & $16.48 \mathrm{c}$ & $22.42 b$ & $26.56 a$ & $26.43 a$ & $25.08 \mathrm{a}$ & 0.95 & 0.0001 \\
\hline \multicolumn{8}{|l|}{ Monounsaturated } \\
\hline C16:1n7 (Palmitoleic) & 4.72 & 2.30 & 2.63 & 3.12 & 3.56 & 1.01 & 0.27 \\
\hline C18:1n9 (Oleic) & 26.41 & 25.41 & 22.93 & 25.65 & 28.29 & 2.57 & 0.24 \\
\hline \multicolumn{8}{|l|}{ Polyunsaturated } \\
\hline C18:2n6 (Linoleic) & $27.18 \mathrm{a}$ & $30.22 \mathrm{a}$ & $30.02 \mathrm{a}$ & $17.54 \mathrm{~b}$ & $23.79 \mathrm{ab}$ & 3.13 & 0.03 \\
\hline Saturated & $32.4 \mathrm{~b}$ & $39.7 \mathrm{ab}$ & $43.5 \mathrm{ab}$ & $49.2 \mathrm{a}$ & $42.4 \mathrm{ab}$ & 5.77 & 0.05 \\
\hline Monounsaturated & 35.4 & 27.4 & 25.1 & 28.7 & 31.8 & 5.55 & 0.25 \\
\hline Polyunsaturated & $31.17 \mathrm{a}$ & $32.1 \mathrm{a}$ & $31.2 \mathrm{a}$ & $20.9, \mathrm{~b}$ & $25.6 \mathrm{ab}$ & 4.23 & 0.04 \\
\hline
\end{tabular}

Means followed by the same letter in the same row do not significantly differ according to Tukey's test at $5 \%$; ${ }^{1}$ Lipid sources: soybean oil (SO); sunflower oil (SFO); cottonseed oil (CO); beef tallow (BT); and poultry fat (PF); ${ }^{2} \mathrm{SEM}=$ Standard error of mean.

$(\mathrm{C} 18: 3 \mathrm{n} 3)$ in meat was observed in rabbits fed diets containing soybean oil compared to those fed with sunflower oil, cottonseed oil and beef tallow, not differing from animals fed poultry fat in the diet. Lower values for C18:2n6:C18:3n3 ratio in meat were observed in rabbits fed soybean oil and poultry fat compared to others lipid sources.

In relation to total polyunsaturated fatty acids in meat, rabbits fed diet containing vegetable oils presented higher levels than those fed diet containing beef tallow, although no difference was observed when compared to those fed with poultry fat in diet.

Although no difference in TBARS values was observed between the refrigerated meat from rabbits fed different dietary lipid sources on day 1 (Table 5), higher values were observed in meat after 12 days of refrigerated storage. After 12 days of storage, the meat from rabbits fed diet containing cottonseed oil showed $(P<0.05)$ higher TBARS value than meat from animals fed other diets.

For meat under frozen storage, on day 1, it was observed that rabbits fed diet with sunflower oil presented higher TBARS
Table 5. TBARS value (mg malonaldehyde/100 g of sample) of meat from rabbits fed diets with different lipid sources after refrigerated and frozen storage.

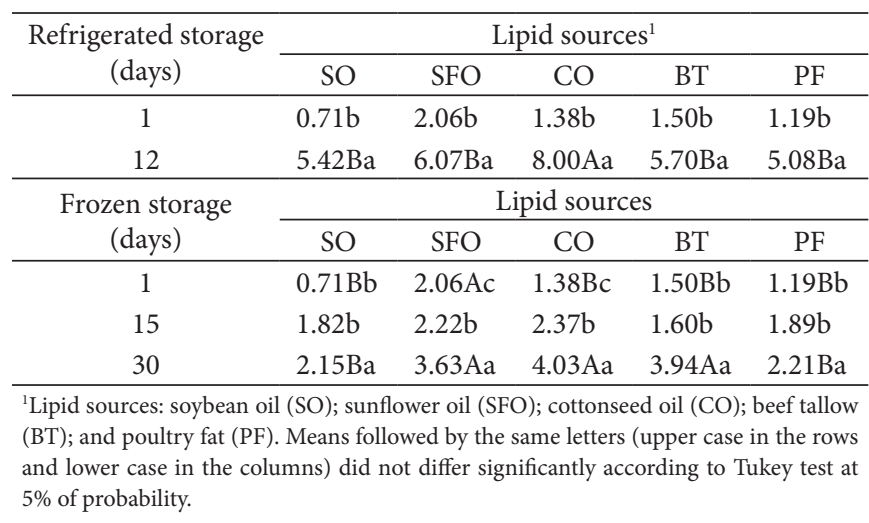

level. After 15 days of storage, no difference in TBARS values was observed among treatments. However, after 30 days, the meat from rabbits fed diets containing soybean oil and poultry 
fat exhibited lower TBARS values than those from animals from other dietary treatments. Regarding the storage period, the meat stored under freezing for 30 days presented higher values of TBARS in relation to the periods of 1 and 15 days of storage.

\section{Discussion}

The inclusion of fat and oils in rabbit diets has been evaluated to increase the energy level in feed, in addition to facilitating the pelleting process by reducing dustiness and maintaining pellet integrity during storage (Muramatsu et al., 2015). Although vegetable oils and animal fats have a different fatty acid composition, considering the isoenergetic diets in the present study, the inclusion of different lipid sources up to $2.5 \%$ resulted in no differences in performance of growing rabbits, confirming the results obtained by Falcão e Cunha et al. (2000) who evaluated the inclusion of up to $3.5 \%$ soybean oil and tallow in growing rabbit diets and found no significant effect on final weight, average daily gain, or feed conversion. Higher levels of dietary vegetable oils and animal fats were evaluated by Ferreira et al. (2006), who observed no effect of the lipid source on the daily weight gain or feed conversion of rabbits.

Likewise, since there was no effect on performance, it was expected that the carcass traits and proximate composition of rabbit meat did not differ from the inclusion of evaluated lipid sources. Similar results were reported by Cobos et al. (1993), who studied the influence of diets containing beef tallow, soybean oil, and sunflower oil and also reported no differences in meat composition of rabbits, corroborating with Fernández \& Fraga (1996) who found that the addition of $3 \%$ beef tallow or soybean oil in rabbit diets did not affect the amount of fat in carcass.

The lower level of palmitic acid (C16:0) in meat of rabbit fed diet with soybean oil could be considered beneficial from the point of view of meat consumption, since this fatty acid is related for elevating the plasma concentrations of total cholesterol and the LDL fraction in humans (Ooi et al., 2015). A similar result to that observed in the present study was obtained by Silva et al. (2009), who evaluated the inclusion of $2.5 \%$ soybean oil in feed, which resulted in a lower palmitic fatty acid content in rabbit meat.

The modulation in fatty acid profile of meat is not exclusively caused by lipid sources, but it is also caused by ingredients with higher lipid contents (Souza et al., 2009), indicating that even with a higher proportion of unsaturated fatty acids, the meat of rabbits can be affected by dietary factors. Thus, the higher content of linoleic acid (the precursor of n-6 fatty acids) in meat of animals fed vegetable oils compared with those fed with animal fat is due to the high content of this fatty acid in soybean, sunflower, and cottonseed oils. Regarding linolenic acid, a higher content of this fatty acid was found in meat from animals fed diet containing soybean oil as main lipid source; this is beneficial from a nutritional standpoint because it is a precursor of the n-3 family of polyunsaturated fatty acids, which benefits to human health are being highlighted (Ooi et al., 2015). In addition, the importance of lower $n-6: n-3$ ratio in meat as observed in rabbits fed soybean oil is related not only to increase n-3 essential fatty acids in human nutrition, but also preventing some correlated diseases such as hypercholesterolemia-related heart attack and strokes (Givens, 2009).

Animals fed diet containing beef tallow exhibited higher saturated and lower polyunsaturated fatty acid contents in their meat than those fed soybean oil, demonstrating the quality of the lipid sources and the possibility of altering the fatty acid composition of meat by including these feedstuffs in animal diets to achieve healthier products. Thus, although some researches aimed at increasing meat enrichment in n-3 fatty acids has been focused on the addition of higher-cost lipid sources (Casado et al., 2013; Trebušak et al., 2014), in the present study it is observed that soybean oil, which is commonly used in rabbit diets, has a potential beneficial effect on increase the level of polyunsaturated fatty acids and contribute to the adequate balance of $n-6: n-3$ ratio of today's consumer diet.

On the other hand, the modulation of fatty acid profile of meat could increase oxidation and lipid peroxidation, thus reducing the shelf life of meat. The TBARS value quantifies the content of malondialdehyde, a secondary product of the decomposition of unsaturated fatty acid hydroperoxides (Ayala et al., 2014), which are formed during the oxidation process; therefore, vegetable oils tend to result in higher values because they present a greater number of unsaturations in their structures. Although higher levels of TBARS were observed in meat under 12 days of refrigeration, similar values between rabbit meat fed diet with animal fat, soybean oil and sunflower oil may be related to the presence of tocopherols which antioxidant effect resulted in the protection of polyunsaturated fatty acids present in these vegetable oils (Grilo et al., 2014).

After freezing, the TBARS value of meat were influenced $(P<0.05)$ by the dietary lipid sources fed to growing rabbits and by the storage period. Following 30 days of frozen storage, the oxidation of lipids was greater for all treatments compared with time 0 , and the treatments involving soybean oil and poultry fat resulted in better oxidative stability. Considering these two sources, the inclusion of soybean oil in growing rabbit diet appears to be more advantageous, as it provides both an increased polyunsaturated fatty acid content and results in greater lipid stability of meat.

\section{Conclusions}

Although the use of different lipid sources in growing rabbit diets has promoted similar performance, it can be concluded that soybean oil is more advantageous because it promotes the incorporation of polyunsaturated fatty acids and greater lipid stability of refrigerated and frozen rabbit meat.

\section{References}

Association of Official Analytical Chemists - AOAC. (1990). Official methods of analysis of the Association of Official Analytical Chemists (15th ed.). Washington: AOAC.

Ayala, A., Muñoz, M. F., \& Argüelles, S. (2014). Lipid peroxidation: production, metabolism, and signaling mechanisms of malondialdehyde and 4-hydroxy-2-nonenal. Oxidative Medicine and Cellular Longevity, 2014, 360438. http://dx.doi.org/10.1155/2014/360438. PMid:24999379. 
Casado, C., Moya, V. J., Fernández, C., Pascual, J. J., Blas, E., \& Cervera, C. (2010). Diet digestibility in growing rabbits: effect of origin and oxidation level of dietary fat and vitamin E supplementation. World Rabbit Science, 18(2), 57-63. http://dx.doi.org/10.4995/WRS.2010.18.08.

Casado, C., Moya, V. J., Pascual, J. J., Blas, E., \& Cervera, C. (2013). Dietary fatty acid profile: effects on caecal fermentation and performance of young and fattening rabbits. World Rabbit Science, 21(4), 235-242. http://dx.doi.org/10.4995/wrs.2013.1437.

Cesari, V., Grilli, G., Ferrazzi, V., \& Toschi, I. (2009). Influence of ate at weaning and nutritive value of weaning diet on growth performance and caecal traits in rabbits. World Rabbit Science, 17, 195-205.

Cobos, A., Cambero, M. I., Ordoñez, J. A., \& De la Hoz, L. (1993). Effect of fat-enriched diets on rabbit meat fatty acid composition. Journal of the Science of Food and Agriculture, 62(1), 83-88. http:// dx.doi.org/10.1002/jsfa.2740620112.

Dalle Zotte, A. (2002). Perception of rabbit meat quality and major factors influencing the rabbit carcass and meat quality. Livestock Production Science, 75(1), 11-32. http://dx.doi.org/10.1016/S03016226(01)00308-6.

El-Husseiny, O., Ghazalah, A. A., Arafa, S. A., \& El-Manylawi, M. A. (2004). Response of growing rabbit performance to some dietary vegetable oils and their Ca-soap. World Rabbit Science, 12, 597-617.

Falcão e Cunha, L., Garcia, P., \& Freire, J. P. B. (2000). Utilização de gorduras - óleo de soja e sebo - no regime alimentar do coelho em crescimento: resultados zootécnicos e digestibilidade. Revista Portuguesa de Zootecnia, 2(1), 87-98.

Fernández, C., \& Fraga, M. J. (1996). The effect of dietary fat inclusion on growth, carcass characteristics, and chemical composition of rabbit. Journal of Animal Science, 74(9), 2088-2094. http://dx.doi. org/10.2527/1996.7492088x. PMid:8880410.

Ferreira, V. P. A., Ferreira, W. M., Saliba, E. O. S., Scapinello, C., Teixeira, A. O., \& Kamwa, E. B. (2006). Digestibilidade, cecotrofia, desempenho e rendimento de carcaça de coelhos em crescimento alimentados com rações contendo óleo vegetal e gordura animal. Revista Brasileira de Zootecnia, 35(4 Suppl.), 1696-1704. http:// dx.doi.org/10.1590/S1516-35982006000600017.

Folch, J., Less, M., \& Stanley, S. (1957). A simple method for the isolation and purification of total lipids from animal tissues. The Journal of Biological Chemistry, 226(1), 497-509. PMid:13428781.

Gidenne, H., Garreau, H., Drouilhet, L., Aubert, C., \& Maertens, L. (2017). Improving feed efficiency in rabbit production, a review on nutritional, technico-economical, genetic and environmental aspects. Animal Feed Science and Technology, 225, 109-122. http:// dx.doi.org/10.1016/j.anifeedsci.2017.01.016.

Givens, I. (2009). Animal nutrition and lipids in animal products and their contribution to human intake and health. Nutrients, 1(1), 7182. http://dx.doi.org/10.3390/nu1010071. PMid:22253968.
Grilo, E. C., Costa, P. N., Gurgel, C. S. S., Beserra, A. F. L., Almeida, F. N. S., \& Dimenstein, R. (2014). Alpha-tocopherol and gamma-tocopherol concentration in vegetable oils. Food Science and Technology, 34(2), 379-385. http://dx.doi.org/10.1590/S0101-20612014005000031.

Klinger, A. C. K., Toledo, G. S. P., Eggers, D. P., Pretto, A., Chimainski, M., \& Silva, L. P. (2015). Soybean hulls on diets for growing rabbits. Ciência Rural, 45(1), 98-103. http://dx.doi.org/10.1590/0103$8478 \mathrm{cr} 20130514$.

Lebas, F. (1999). Recomendações alimentares: alimentação dos coelhos (2nd ed., pp. 76-84). São Paulo: Roca.

Muramatsu, K., Massuquetto, A., Dahlke, F., \& Maiorka, A. (2015). Factors that affect pellet quality: a review. Journal of Agricultural Science and Technology, 5, 717-722.

Ooi, E. M. M., Watts, G. F., Ng, T. W. K., \& Barrett, P. H. R. (2015). Effect of dietary fatty acids on human lipoprotein metabolism: a compreensive update. Nutrients, 7(6), 4416-4425. http://dx.doi. org/10.3390/nu7064416. PMid:26043038.

Petracci, M., Bianchi, M., \& Cavani, C. (2009). Development of rabbit meat products fortified with n-3 polyunsaturated fatty acids. Nutrients, 1(2), 111-118. http://dx.doi.org/10.3390/nu1020111. PMid:22253971.

Raharjo, S., Sofos, N. J., \& Schmidt, R. G. (1992). Improved speed, specificity, and limit of determination of an aqueous acid extraction thiobarbituric acid- $\mathrm{C}_{18}$ method for measuring lipid peroxidation in beef. Journal of Agricultural and Food Chemistry, 40(11), 2182-2185. http://dx.doi.org/10.1021/jf00023a027.

Silva, W. R., Scapinello, C., Furlan, A. C., Murakami, A. E., Moreira, I., \& Martins, E. N. (2009). Perfil de ácidos graxos da carcaça de coelhos desmamados em diferentes idades e condições de alimentação, recebendo dietas com ou sem óleo de soja. Acta Scientiarum. Animal Sciences, 31, 257-263.

Souza, D. V., Zapata, J. F. F., Freitas, E. R., Souza Neto, M. A., Pereira, A. L. F., Vidal, T. F., Abreu, V. K. G., \& Silva, E. M. C. (2009). Fatty acid profile and proximal composition of meat from rabbits fed diets containing coconut meal. Food Science and Technology, 29(4), 778-784.

Trebušak, T., Levart, A., Frankič, T., \& Pirman, T. (2014). Effect of dietary linseed oil and Ganoderma lucidum olive leaves supplementation on fatty acid composition and oxidative status of rabbits. World Rabbit Science, 22(1), 71-81. http://dx.doi.org/10.4995/wrs.2014.1183.

Tres, A., Bou, R., Codony, R., \& Guardiola, F. (2008). Influence of different dietary doses of n-3- or n-6-rich vegetable fats and alphatocopheryl acetate supplementation on raw and cooked rabbit meat composition and oxidative stability. Journal of Agricultural and Food Chemistry, 56(16), 7243-7253. http://dx.doi.org/10.1021/jf800736w. PMid:18627165. 